\title{
180 DEGREES TORSION OF THE TERM GRAVID UTERUS -A CASE REPORT ON THIS RARE OBSTETRIC EMERGENCY
}

Urmila Tripathi' ${ }^{1}$, Yogendra Tripathi ${ }^{2}$.

1. Assistant. Professor,Department of Obstetrics \& Gynaecology, G.R. Medical College, Gwalior, Madhya Pradesh.

2. Ex-Consultant Surgeon,Department of Obstetrics \& Gynaecology,NIOC Field Hospital, Omediyeh, Khozistan,IRAN

\section{CORRESPONDING AUTHOR}

Dr. Urmila Tripathi,

C-98, Govind Puri, Opp. Vice Chancellor's Residence,

Hurawali Road, Gwalior,

Madhya Pradesh, Pin Code No 474011.

Email: urmilatripathi@gmail.com

HOW TO CITE THIS ARTICLE: Urmila Tripathi, Yogendra Tripathi. "180 Degrees Torsion of the Term Gravid Uterus -A Case Report on this Rare Obstetric Emergency". Journal of Evolution of Medical and Dental Sciences 2013; Vol2, Issue 23, June 10; Page: 4055-4057.

INTRODUCTION; Uterine torsion is defined as a rotation of the uterus of more than 45 degrees on its long axis. It is an unusual complication of pregnancy and for most obstetricians it probably represents a 'once in a lifetime' diagnosis (1). Uterine torsion usually ranges from 45 degrees to 180 degrees but some cases of torsion of up to 720 degrees have also been reported (2). Until 1992, only 212 cases had been reported in literature (3). Dextrorotation occurs in two thirds of the cases and levorotation is found in the other one third (4).

CASE REPORT: A 42 year old G10P7A2 having gestational diabetes and mild to moderate PIH was under antenatal case in specialist obstetric clinic from the fifth month of pregnancy. She had seven full term vaginal deliveries. On the first visit, O/E Ht 5'3", wt 60kgs pulse 80/min BP 140/90, no anaemia, no edema feet. P/A very lax pendulous abdomen, uterus 18 weeks, 0/E external ballotment present, lie unstable, FHS $140 / \mathrm{min}$. Sonography confirmed fetus in oblique lie and of a corresponding gestational age, placenta fundal. In eighth month fetus continued in the oblique lie, BP in the range of $140 / 90$ to $170 / 100 \mathrm{~mm} \mathrm{Hg}$. She was under antihypertensive and supportive treatment and diet modification for her gestational diabetes.

One noon she presented with complaints of breathlessness, sweating and vertigo. O/E pulse 100/min, BP-100/60 mm Hg, pallor present. P/A uterus 36 weeks, mildly contracted FHR 170/min. $\mathrm{P} / \mathrm{V}$ cervix $2 \mathrm{~cm}$ dilated, high up, presenting part not reached by the examining fingers .No leaking, no bleeding P/E and no edema feet.

Immediate emergency treatment was given- oxygen, left lateral position and I/V fluids, urgent blood and urine tests were sent. Patient catheterized. The patient's only complaint was giddiness and breathlessness. She refused experiencing any pain in abdomen. In an hour or so her general condition deteriorated and she also complained of pain in abdomen now. The uterus had increased in size and became firm and tender too. The FHS were lost and intermittent painful uterine contractions had set in.

On the provisional diagnosis of abruption placenta the patient was taken for emergency caesarean section and three units of blood arranged. Her BP had dropped to 70mm Hg systolic and 
she was very pale. I/V drips were running in both hands and venesection done in left foot and blood transfusion started. Under general anaesthesia, the abdomen was opened by vertical low midline incision. The uterus was couvelaire and over distended. Loose peritoneum over the lower uterine segment was not discerned. A low midline vertical incision was given on the lower uterine segment as the lower segment appeared not formed. A fresh still birth female baby of $2.5 \mathrm{~kg}$ was delivered by breech followed by huge retro placental clots of about 2000-2500 cc. 40 units oxytocin in 1000 cc dextrose saline running fast and uterine massage alone were sufficient to bring about adequate uterine contraction.

While I was quickly suturing the second layer of uterine incision I found the adnexa much taut and heavy venous congestion in both broad ligaments. It was then that I discovered that the whole uterus had undergone anticlockwise torsion by 180 degree and the baby had been extracted from the posterior lower uterine segment. The uterus was untwisted and tubal ligation done. She received three units blood intraoperatively and three unit fresh blood in the next 48 hours. Postoperative period was uneventful and she was discharged on the tenth day with a healthy wound and $\mathrm{Hb} 13 \mathrm{gm} \%$.

DISCUSSION: The exact mechanism and aetiology of torsion is not known. It has been noted to occur in the presence of intra-abdominal adhesions, ovarian tumors and fetal malpresentations. Robinson \& Duvall proposed that certain maternal irregular body movements or posture and positions may help trigger the rotation of a uterus with pre-existing structural pathology and intrinsic pelvic pathology is found in 66 percent of cases of uterine torsion (5).

More recently, cases have been reported with no associated pelvic factors although a common feature in these cases has been a previous caesarean section. A study of magnetic resonance imaging evaluation of patients following low transverse caesarean section suggested that in rare instances poor isthmic healing may result in suboptimal restoration of normal cervical length in these cases (6). This results in an elongated cervix with structural weakness and angulation in the isthmic region leading to torsion. Uterine torsion resulting from abdominal trauma has also been reported (7). The occurrence is independent of maternal age, parity and gestation (1).

In our case, the cause of such complete torsion was transverse lie in the pendulous abdomen in a grand multipara.

The clinical presentation of torsion is non-specific. The most common symptom is abdominal pain however this may vary from non-specific mild abdominal discomfort through to symptoms of an acute abdomen with shock, thus making diagnosis difficult. In around 11 percent of cases torsion is asymptomatic (3).

Torsion presenting in labour may manifest itself by failure of cervical dilatation despite strong uterine contractions or fetal distress due to reduction in uterine blood flow. Other clinical signs like vaginal bleeding, uterine tenderness, twisted vaginal canal and urethral displacement may also be seen. Some authors have described use of an ultrasound scan to establish a diagnosis, which may show a change in placental localization or a change in the position of fibroid (1). Nicholson et al suggested use of pelvic MRI to diagnose uterine torsion, which may show an Xshaped configuration of the upper vagina (8). Patients with acute symptoms or with suspected uterine torsion should have a laparotomy. In cases of torsion recognised at term, manual correction 
followed by delivery of the fetus by a caesarean section is the treatment of choice. In cases where correction is not possible, a deliberate posterior hysterotomy can be done for delivery of fetus. Bilateral plication of the round ligaments can be done to prevent immediate post-partum recurrence of uterine torsion (9). This may help to keep the uterus in anteversion, reduce posterior uterine adhesions and future dyspareunia. Mustafa et al described bilateral plication of uterosacral ligaments, which may provide resistance to torsion and prevent long-term recurrence of uterine torsion (10).

This condition is associated with significant mortality and morbidity. The perinatal mortality has been reported to be $12 \%$ (3). Overall the maternal mortality is around $13 \%$ and is directly proportional to the duration of gestation and degree of torsion (11). However, since 1960, only one maternal death due to uterine torsion has been reported (12).

CONCLUSION: Uterine torsion is a rare complication of pregnancy and obstetricians should have this complication in mind when performing a caesarean section on a woman with abnormal presentation of the fetus, adhesions, uterine myomas, uterine abnormalities or ovarian tumor. In cases with acute abdominal pain during pregnancy, uterine torsion should be included in differential diagnosis, especially in presence of uterine pathology. Anatomical landmarks should always be defined prior to uterine incision during a caesarean section, to prevent damage to uterine vessels and to check for any degree of torsion of the pregnant uterus.

\section{REFERENCES}

1. Kremer JAM, van Dongen P WJ. Torsion of the pregnant uterus with a change in placental localization on ultrasound; a case report. Eur J Obstet Gynecol Reprod Biol. 1989; 31: 273-275.

2. Corr JE. Axial torsion of the gravid uterus in two successive pregnancies. Am J Obstet Gynecol. 1943; 46: 749-751.

3. Jenson JG. Uterine torsion in pregnancy. Acta Obstet Gynecol Scand.1992; 71: 260-265.

4. Barber HRK, Graber EA. Uterine Torsion during pregnancy. In: Surgical disease in pregnancy. Philadelphia: WB Saunders Co Ltd, 1974: 387-388.

5. Robinson AL, Duvall HM. Torsion of the pregnant uterus. J Obstet Gynaec Br Commonw. 1931; 38: 5584.

6. Kawakami S, Togashi K, Sagoh T, Kimura I, Noguchi M, Takakura K, Mori T, Konishi J. Uterine deformity caused by surgery during pregnancy. J comput Assist Tomogr. 1994; 18: 272-274.

7. Duplantier N, Begneaud W, Wood R, Dabezies C. Torsion of gravid uterus associated with maternal trauma. A case report. J Reprod Med. 2002; 47: 683-685.

8. Nicholson WK, Coulson CC, McCoy CM, Semelka RC. Pelvic magnetic resonance imaging in the evaluation of uterine torsion. Obstet \& Gynecol. 1995; 85: 888-890.

9. Pelosi MA 3rd, Pelosi MA. Managing extreme uterine torsion at term: A case report. J Reprod Med. 1998; 43: 153-157.

10. Mustafa MS, Shakeel F, Sporrong B. Extreme torsion of the pregnant uterus. Aust NZ J Obstet Gynaecol. 1999; 39: 360-363.

11. Nesbitt REL, Corner GW. Torsion of the human pregnant uterus. Obstet Gynecol Surv. 1956; 11: 311332.

12. Guie P et al. Uterine torsion with maternal death: Our experience and literature review. Cli Exp Obst \& Gyn. 2005; 32: 245-246. 